\title{
The Anti-apoptotic Action of 5-Hydroxyindole: Protection of Mitochondrial Integrity
}

\author{
Sung Jin BAe, ${ }^{a, b}$ Jun Sik LeE, ${ }^{\mathrm{c}}$ Eun Kyeong Lee, ${ }^{a, b}$ Ji Min Kim, ${ }^{a, b}$ Jehun Chor ${ }^{a, b}$ Hyoung-Sam Heo, ${ }^{a, b}$ \\ Byung Pal Yu, ${ }^{d}$ and Hae Young $\mathrm{CHUNG}^{*, a, b}$ \\ ${ }^{a}$ Department of Pharmacy, Pusan National University; ${ }^{b}$ Molecular Inflammation Research Center for Aging Intervention \\ (MRCA), College of Pharmacy, Pusan National University; Busan 609-735, Korea: ' Department of Microbiology and \\ Immunology, College of Medicine, BK21 Medical Science Education Center, Pusan National University; Busan 602-739, \\ Korea: and ${ }^{d}$ Department of Physiology, The University of Texas Health Science Center at San Antonio; San Antonio, TX \\ 78229-3900, U.S.A. Received September 9, 2009; accepted December 9, 2009; published online February 1, 2010
}

5-Hydroxyindole (5HI), a metabolite of tryptophan, is involved in learning and memory, central neuron system regulation, and anti-oxidant activity. However, its protective action in mitochondrial function is not clear. Here, we tested whether $5 \mathrm{HI}$ protects against tert-butylhydroperoxide (t-BHP)-induced oxidative damage and mitochondrial dysfunction in human fibroblast cells. 5HI significantly suppressed $t$-BHP-induced cytotoxicity as determined by intracellular reactive species generation, lipid peroxidation, glutathione depletion, and peroxynitrite $\left(\mathrm{ONOO}^{-}\right)$generation. In addition, $5 \mathrm{HI}$ reduced $t$-BHP-induced DNA condensation. Pretreatment with 5HI significantly restored mitochondrial membrane potential $(\Delta \psi \mathrm{m})$, suggesting that it protected cells against $t$-BHPinduced apoptosis. Western blot analysis also revealed that $5 \mathrm{HI}$ markedly inhibited cytochrome $c$ release and caspase-3 activation, but not caspase-9 activation. Our data suggest that $5 \mathrm{HI}$ protects cells by attenuating oxidative stress and consequently protects against mitochondrial dysfunction.

Key words 5-hydroxyindole; oxidative stress; mitochondrial dysfunction; apoptosis

5-Hydroxyindole (5HI) is a metabolite of tryptophan that is involved in learning and memory as well as in central nervous system regulation, such as in blocking desensitization. ${ }^{1)}$ 5HI also has anti-oxidant activity, ${ }^{2,3)}$ but its cellular targets are unclear.

Oxidative stress can be induced by endogenous processes in which the balance between reductants and oxidants becomes slanted towards the oxidative side. Most oxidants are derived from oxygen and nitrogen based reactive species (RS), including reactive oxygen species (ROS) and lipid peroxidation byproducts. ${ }^{4)}$ ROS cause oxidative modification and play important roles in abnormal pathological processes and biochemical functions. ${ }^{5,6)}$ ROS also can induce apoptosis in many different cell systems. ${ }^{7)}$ tert-Butylhydroperoxide ( $t$ BHP) can cause oxidative stress and cell damage. ${ }^{8)} t$-BHP is a strong RS inducer of lipid peroxidation, and causes glutathione $(\mathrm{GSH})$ depletion and peroxynitrite $\left(\mathrm{ONOO}^{-}\right)$generation. ${ }^{9}{ }^{10)}$ A short-chain analog of lipid hydroperoxides, $t$-BHP is used often as a model compound to establish the mechanism of cell damage initiated by oxidative stress. ${ }^{8)}$

Mitochondrial integrity is constantly threatened by the presence of RS produced in the membrane. High RS levels in the mitochondria can compromise mitochondrial membrane potential $(\Delta \psi m)$, leading to depolarization ${ }^{11)}$ and apoptotic events, including cytochrome $c$ release and caspase activation. ${ }^{12)}$ Here, we attempted to identify the cellular mechanisms of 5HI by focusing on mitochondria and associated apoptotic processes. Our findings show that $5 \mathrm{HI}$ treatment inhibited damage from oxidative stress and apoptosis in $t$ BHP-induced human fibroblast cell. These findings are supported by the data gained on GSH, lipid peroxidation, RS generation, DNA damage, decreased mitochondrial membrane potential, cytochrome $c$ release, and caspase activity.

\section{MATERIALS AND METHODS}

Materials Human fibroblasts were obtained from the American Type Culture Collection (ATCC, Manassas, VA, U.S.A.). 5HI and Dulbecco's modified Eagle's media (DMEM) were purchased form Sigma-Aldrich Chemical (St. Louis, MO, U.S.A.), as were all reagents unless otherwise stated. Fetal bovine serum (FBS), trypsin-ethylenediamineteraacetic acid, and penicillin-streptomycin were purchased from Gibco BRL (Ground Island, NY, U.S.A.). 3(4,5-Dimethylthiazol-yl)-diphenyl tetrazolium bromide (MTT) was provided by DUCHEFA Biochemie (Haarlem, Netherlands). Antibodies for human cytochrome $c$, cleavedcaspase-3, and caspase-9 were purchased from Santa Cruz Biotechnology (Santa Cruz, CA, U.S.A.). Human $\alpha$-tubulin antibody and $2^{\prime}, 7^{\prime}$-dichlorodihydrofluorescein diacetate (DCFDA) were obtained from Sigma-Aldrich (St. Louis, MO, U.S.A.) Horseradish peroxidase-conjugated goat antirabbit immunoglobulin $\mathrm{G}$ (IgG) and goat anti-mouse IgG was provided by Santa Cruz (Santa Cruz, CA, U.S.A.). 5HI was dissolved in dimethyl sulfoxide (DMSO), and the final concentration of DMSO was $<0.1 \%$.

Cell Culture and MTT Assay Human fibroblast cells were cultured in DMEM containing 10\% FBS, 2 mm glutamine, $100 \mathrm{U} / \mathrm{ml}$ penicillin, and $100 \mu \mathrm{g} / \mathrm{ml}$ streptomycin at $37^{\circ} \mathrm{C}$ in a humidified atmosphere of $5 \% \mathrm{CO}_{2}$ in air. Fibroblast cells were used at $90-95 \%$ confluence. $5 \mathrm{HI}$ at less than $<40 \mu \mathrm{M}$ was not toxic over $24 \mathrm{~h}$, as determined by the MTT assay to quantitate cellular viability. Human fibroblast cells were incubated in fresh medium containing $0.5 \mathrm{mg} / \mathrm{ml}$ MTT for $4 \mathrm{~h}$ at $37^{\circ} \mathrm{C}$. After removal of unconverted MTT, the purple formazan product was dissolved in $0.5 \mathrm{ml}$ DMSO through shaking. The absorbance of formazan dye was measured colorimetrically at $\lambda=570 \mathrm{~nm}$.

DAPI Staining Cell death was studied morphologically using a fluorescent nuclear dye, 4,6-diamidino-2-phenlylin- 
dole (DAPI). Apoptotic cells contain condensed chromatin and show nuclear fragmentation that produces the characteristic irregular staining. Cells treated with $5 \mathrm{HI}$ and $20 \mu \mathrm{M} t$ BHP were washed with phosphate buffered saline (PBS). Cells were fixed with $4 \%$ paraformaldehyde and permeabilized by incubation in $0.1 \%$ sodium citrate containing $0.1 \%$ Triton X-100 for $5 \mathrm{~min}$ at $4{ }^{\circ} \mathrm{C}$. They were then stained with DAPI $(1 \mu \mathrm{g} / \mathrm{ml})$ solution for $30 \mathrm{~min}$ at $25^{\circ} \mathrm{C}$ and examined by fluorescence microscopy under blue light (BX50-FLA, Olympus).

Lipid Peroxidation Assay and RS Production Plasma malondialdehyde (MDA) levels were measured using the method described by Draper and Hadley. ${ }^{13)}$ The color produced by the reaction of thiobarbituric acid with MDA was measured at $533 \mathrm{~nm}$, and the result is expressed as pmol of $\mathrm{MDA} / \mathrm{mg}$ protein. The intracellular generation of RS was measured using carboxy- $\mathrm{H}_{2} \mathrm{DCF}-\mathrm{DA}$, a cell-permeable dye. Inside the cells, this compound is oxidized by $\mathrm{RS}$ to form fluorescent carboxydichlorofluorescein (DCF). Briefly, cells seeded in six-well plates at $1 \times 10^{5}$ cells/well and treated with or without $5 \mathrm{HI}$ and $t$-BHP were incubated with $10 \mu \mathrm{M}$ carboxy- $\mathrm{H}_{2} \mathrm{DCF}-\mathrm{DA}$ at $37^{\circ} \mathrm{C}$ for $10 \mathrm{~min}$. The cells were then washed twice with PBS. The rate of oxidation of the dye in the cells was monitored by flow cytometry.

GSH Assay Twenty-four hours after passage of cells into $60 \mathrm{~mm}$ culture dishes, the cells were incubated with $5 \mathrm{HI}$ and $t$-BHP for $24 \mathrm{~h}$. The medium was aspirated, and the cells were washed twice with PBS. One milliliter of $10 \%$ trichloroacetic acid was added to each dish, and the sample was left on ice for $30 \mathrm{~min}$. The mixture was sonicated and centrifuged at $12000 \mathrm{rpm}$ for $10 \mathrm{~min}$. Reduced GSH was measured fluorometrically using the fluorochrome orthophthalaldehyde by the method of Hissin and Hilf. ${ }^{14)}$

Measurement of $\mathrm{ONOO}^{-} \mathrm{ONOO}^{-}$generation was assessed by $\mathrm{ONOO}^{-}$-dependent oxidation of dihydrorhodamine 123 (DHR123) to rhodamine 123 (RH123), as described previously. ${ }^{15)}$ Cells were incubated with DHR123 (20 $\mu \mathrm{M}$, Molecular Probes, Eugene, OR) for $30 \mathrm{~min}$ and the fluorescence of RH123 was measured. Briefly, cells seeded in six-well plates at $1 \times 10^{5}$ cells/well and treated with $5 \mathrm{HI}$ and $t$-BHP were incubated with $20 \mu \mathrm{M}$ DHR 123 at $37^{\circ} \mathrm{C}$ for $30 \mathrm{~min}$. The cells were then washed twice with $\mathrm{PBS}$. The rate of oxidation of the dye in the cells was monitored by flow cytometry.

Determination of Mitochondrial Membrane Potential $(\Delta \boldsymbol{\psi} \mathbf{m})$ For the determination of mitochondrial membrane potential, cells were incubated with carbocyanines dye $\mathrm{DiOC}_{6}(3)$ for $30 \mathrm{~min}$ in the dark at $37^{\circ} \mathrm{C}$ and then harvested and suspended in cold PBS. The mitochondrial membrane potential was measured by flow cytometry.

Measurements of Cytochrome $c$, Caspase-9, and Caspase-3 Expression Human fibroblast cells were lysed in an ice-cold, whole-cell lysate buffer containing $50 \mathrm{~mm} \mathrm{~N}$-(2hydroxyethyl)piperazine- $N^{\prime}$-2-ethanesulfonic acid ( $\left.\mathrm{pH} 7.5\right)$, $150 \mathrm{~mm} \mathrm{NaCl}, 10 \%$ glycerol, $1 \%$ Triton X-100, $1.5 \mathrm{~mm}$ magnesium chloride hexahydrate, $1 \mathrm{~mm}$ ethyleneglycol-bis- $(\beta$ aminoethylether)- $N, N^{\prime}$-tetraacetic acid, $1 \mathrm{~mm}$ phenylmethylsulfonyl fluoride, $2 \mu \mathrm{g} / \mathrm{ml}$ leupeptin, $1 \mu \mathrm{g} / \mathrm{ml}$ pepstatin, $1 \mathrm{~mm}$ sodium orthovanadate, and $100 \mathrm{~mm}$ sodium fluoride for $30 \mathrm{~min}$ at $4{ }^{\circ} \mathrm{C}$. Cell debris was removed by microcentrifugation, and supernatants were quickly frozen. Protein concentrations were measured using Bio-Rad colorimetric protein assay kits (Bio-Rad, Hercules, CA, U.S.A.). Proteins $(20 \mu \mathrm{g})$ were separated on $12 \%$ sodium dodecyl sulfate-polyacrylamide gels and transferred to nitrocellulose membranes (Schleicher \& Schuell GmbH, Dassel, Germany). Anti- $\alpha$ tubulin, anti-cytochrome $c$, anti-caspase-9, and anti-caspase3 antibodies (Cell Signal, Danvers, MA, U.S.A.) were used as primary antibodies and horseradish peroxidase-conjugated anti-rabbit and anti-mouse antibodies (Amersham Pharmacia Biotech GmbH, Freiburg, Germany) were used as the secondary antibodies. Bands were detected by enhanced chemiliminescence kits.

Statistical Analysis The data given in the text are expressed as the mean \pm S.D. Statistical comparisons were performed using one-way ANOVA analysis, with significance at $* p<0.05$.

\section{RESULTS}

5HI Protects Human Fibroblasts against $t$-BHP-Induced Oxidation We first tested whether 5HI protect against $t$-BHP-induced cytotoxicity, which produces free radicals leading to oxidative stress in the cellular system. ${ }^{16)}$ The results in Fig. 1A show a cytoprotective 5HI concentration at $20 \mu \mathrm{M}$ and cytotoxicity at $40 \mu \mathrm{M}$. The $t$-BHP $(20 \mu \mathrm{M})$ induced cell death at $58.9 \pm 1.5 \%$ as shown by the MTT assay, and the $\mathrm{IC}_{50}$ was used for further experiments. Pretreatment with $5 \mathrm{HI}$ (10 or $20 \mu \mathrm{M}$ ) inhibited $t$-BHP-induced cell cytotoxicity, producing $82 \pm 5.5 \%$ survival (Fig. 1B). Because $t$-BHP is known to induce DNA damage, ${ }^{17-19)}$ we assessed DNA condensation using DAPI staining. Treatment with $t$-BHP for $24 \mathrm{~h}$ caused approximately $70 \%$ of cells to show condensed DNA (Fig. 2). 5HI dose-dependently inhibited this DNA condensation (Fig. 2).
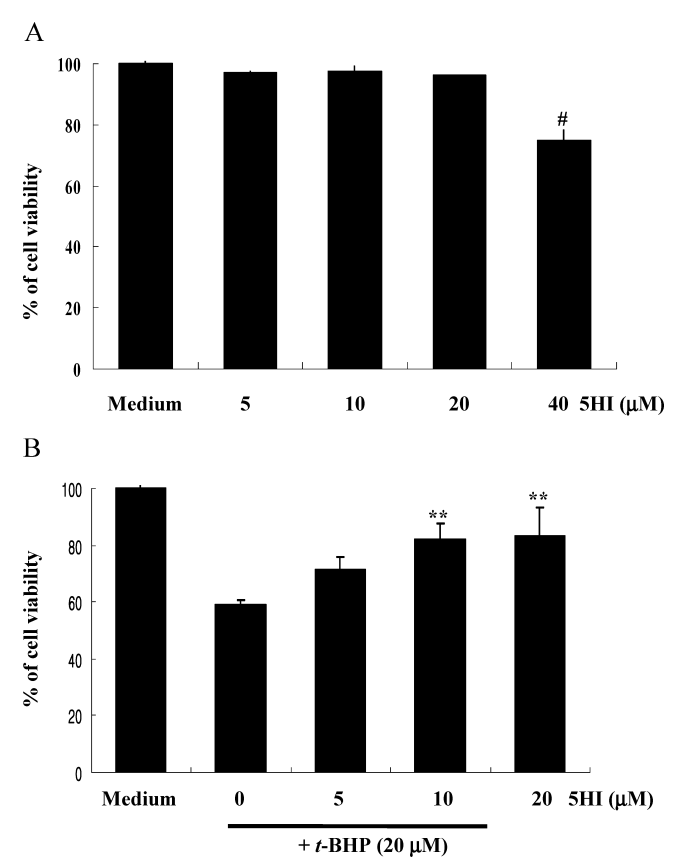

Fig. 1. Effect of 5HI on the Cytotoxicity of Human Fibroblasts by $t$-BHP Cells $\left(1 \times 10^{5}\right)$ placed in 24 -well plates were incubated with $0,5,10,20$, or $40 \mu \mathrm{m}$ of $5 \mathrm{HI}$ for $24 \mathrm{~h}$ (A). Cells were pre-incubated with 5,10 , or $20 \mu \mathrm{M} 5 \mathrm{HI}$ for $2 \mathrm{~h}$ and then incubated with $20 \mu \mathrm{M} t$-BHP or DMSO $(0.5 \%, \mathrm{v} / \mathrm{v}$, as control (medium group)) for another $24 \mathrm{~h}$ (B). Results represent the mean \pm S.D. of four independent experiments; ${ }^{\#} p<0.05 \mathrm{vs}$. control, $* * p<0.01 \mathrm{vs}$. the group treated with $t$-BHP. 

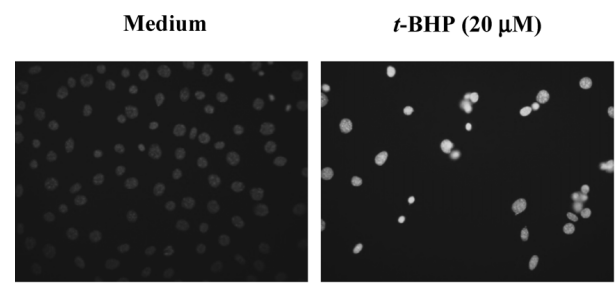

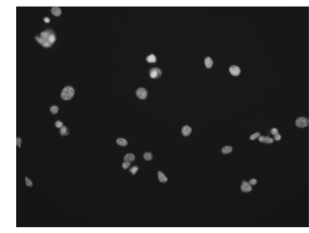

5

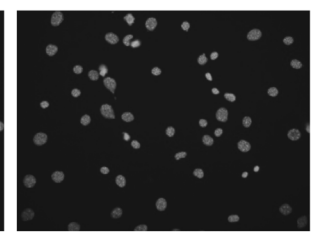

10

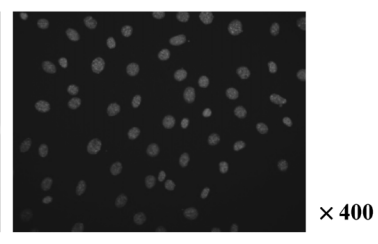

$20 \quad 5 H I(\mu M)$

$+t$-BHP $(20 \mu \mathrm{M})$

Fig. 2. Effect of 5HI on $t$-BHP-Induced DNA Damage in the DAPI Assay

Cells were pre-incubated with $5 \mathrm{HI}$ for $2 \mathrm{~h}$ and then were incubated with $20 \mu \mathrm{M} t$-BHP for another $24 \mathrm{~h}$. DNA damage was determined using the DAPI assay. DAPI-stained cells were observed by fluorescence microscopy $(400 \times)$. The results are representative of three independent experiments.

5HI Attenuates $t$-BHP-Induced Lipid Peroxidation and GSH Depletion MDA and GSH levels were measured as markers of oxidative stress-induced cell damage. ${ }^{20,21)}$ We examined whether 5HI repairs the induction of lipid peroxidation and GSH depletion by $t$-BHP. 5HI alone did not change MDA levels, but did block the increases in MDA and GSH depletion caused by $t$-BHP (Figs. 3A, B).

5HI Suppresses $t$-BHP-Induced ROS and NOO $^{-}$ Generation by $\mathbf{5 H I}$ in Human Fibroblast Cells ROS and $\mathrm{ONOO}^{-}$are strong oxidants that can initiate lipid peroxidation, GSH depletion, and DNA damage. ${ }^{22,23)} t$-BHP induces cell death through the generation of ROS and $\mathrm{ONOO}^{-8,16)}$ Treatment of human fibroblasts with $t$-BHP for $12 \mathrm{~h}$ increased levels of ROS (from $21 \pm 1.2 \%$ to $38 \pm 1.4 \%$ ) and $\mathrm{ONOO}^{-}(27 \pm 2.6 \%, 42 \pm 2.0 \%)$. Pretreatment with $5 \mathrm{HI}$ for $2 \mathrm{~h}$ dose-dependently decreased ROS and $\mathrm{ONOO}^{-}$(Figs. 4A, $\mathrm{B})$. These data indicate that $5 \mathrm{HI}$ strongly inhibited $t$-BHPinduced ROS and $\mathrm{ONOO}^{-}$generation as well as oxidative stress, including MDA and GSH depletion.

5HI Protects Mitochondria against $\boldsymbol{t}$-BHP-Induced Oxidative Insult and Caspase Activation Mitochondria play an important role in cell death triggered by many stimuli, including ROS. ROS generation modifies mitochondria membrane potential $(\Delta \psi \mathrm{m})$. We therefore monitored $\Delta \psi \mathrm{m}$ following $t$-BHP treatment using $\mathrm{DiOC}_{6}(3)$ and flow cytometry. A decrease in $\Delta \psi \mathrm{m}$ occurred at $4 \mathrm{~h}$, and the loss in $\Delta \psi \mathrm{m}$ became significant at $6 \mathrm{~h}$ and $9 \mathrm{~h}$ (Fig. 5A). Pretreatment with $5 \mathrm{HI}$ reversed the reduction of $\Delta \psi \mathrm{m}$ in a dose-dependent manner (Fig. 5B). Cytochrome $c$ release from mitochondria during a cell damage initiates caspase-dependent apoptosis pathways. $^{24)}$ 5HI suppressed the cytochrome $c$ release by $t$-BHP and inhibited caspase- 3 activation, but not caspase-9 activation (Fig. 5C). These data indicate that 5HI inhibits $t$-BHP-induced cell death by regulating $\Delta \psi \mathrm{m}$ depolarization caspase 9-independent and caspase 3-dependent pathways.

\section{DISCUSSION}

This is the first report on the effects of 5HI on oxidative stress and is also the first study in which $t$-BHP treated human fibroblasts have been analyzed for oxidative stress
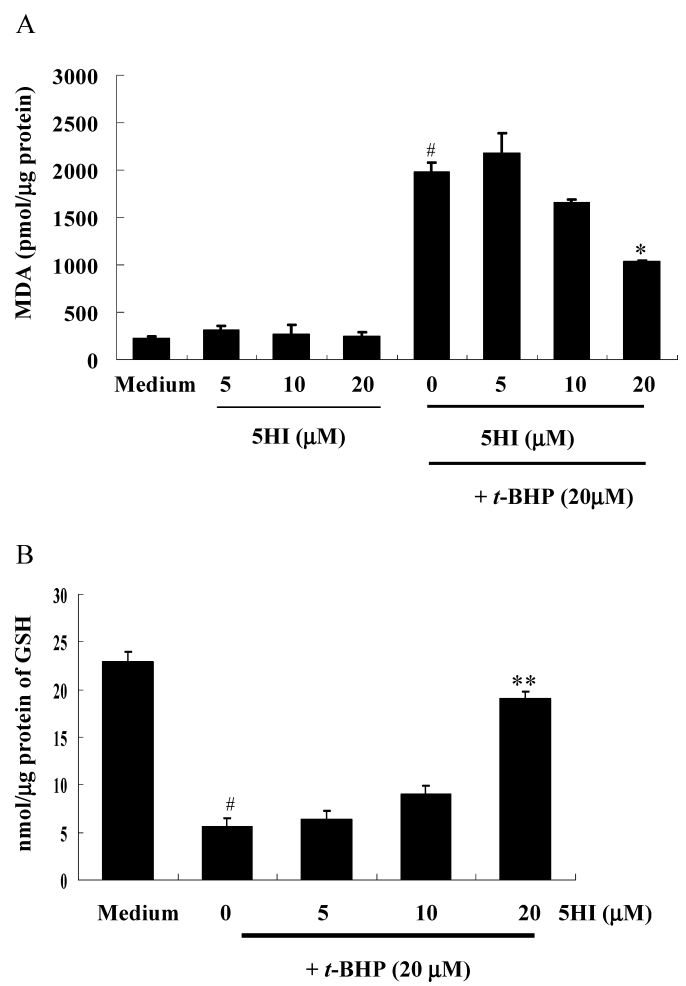

Fig. 3. Effect of 5HI on MDA Production and GSH Depletion Induced by $t$-BHP

Cells were pre-incubated with $5 \mathrm{HI}$ for $2 \mathrm{~h}$ and then were incubated with $t$-BHP $(20 \mu \mathrm{M})$ for another $24 \mathrm{~h}$. After incubation, lipid peroxidation was evaluated by the MDA assay (A) and GSH levels by the GSH assay (B). The results are representative of three independent experiments. $\# p<0.05$ vs. control, $* p<0.05, * * p<0.01$ vs. the group treated with $t$-BHP.

and mitochondrial dysfunction from oxidative damage. Cadenas et al. have reported the antioxidant activity of $5 \mathrm{HI}$ in Fe-induced lipid peroxidation of liver microsomes, ${ }^{2)}$ and recently, the putative protective role of 5HI was reported in its ability to suppress cell death and cytochrome $c$ release from mitochondria that was induced by 1-methyl-4-phenylpyridinium. ${ }^{25-27)}$ However, the exact modulation pathways of $5 \mathrm{HI}$ remain unclear. Moreover, the effects of 5HI on oxidative mitochondrial damage in human fibroblasts remain 
$\mathbf{A}$ $+t$-BHP $(20 \mu \mathrm{M})$
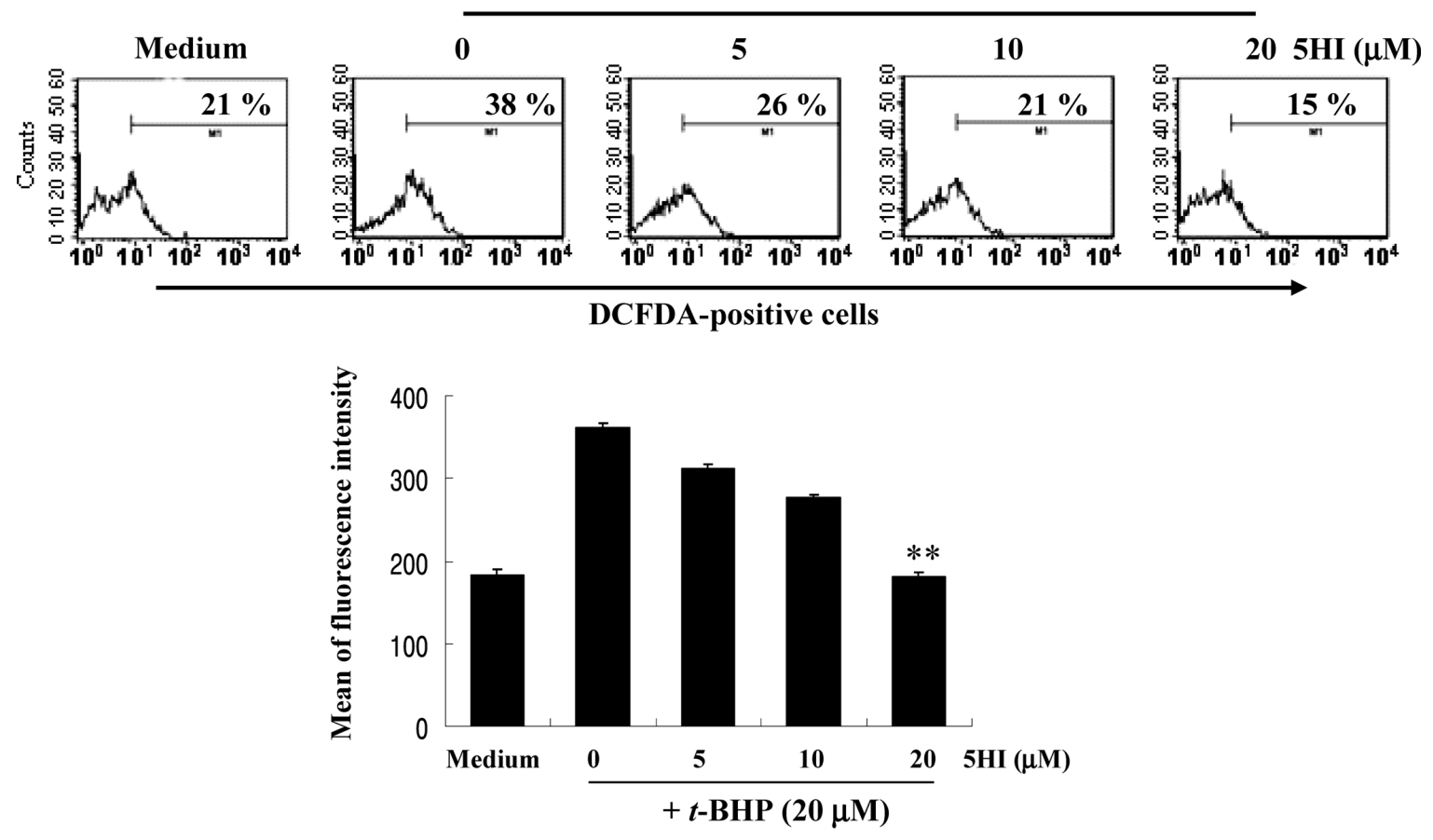

B
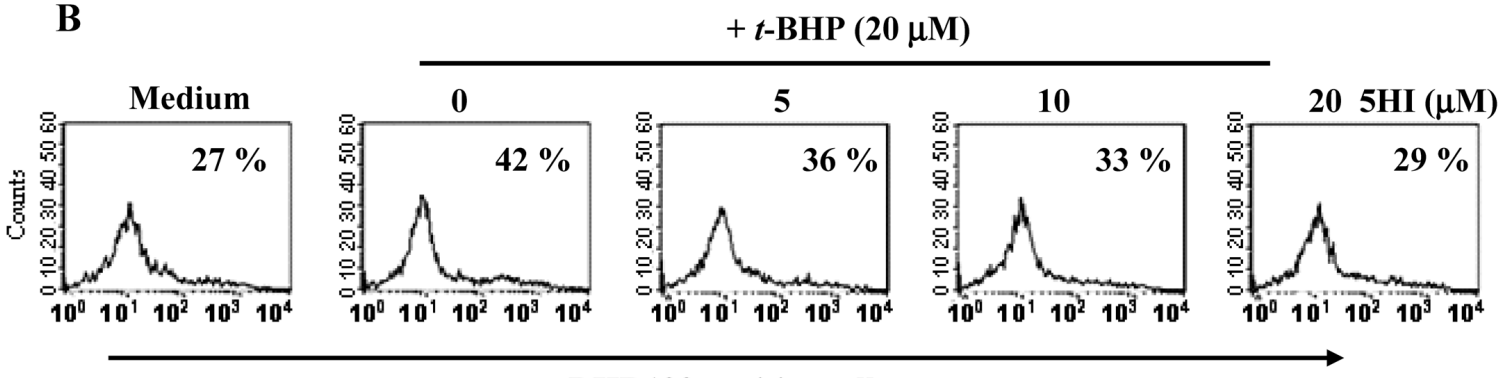

DHR123-positive cells

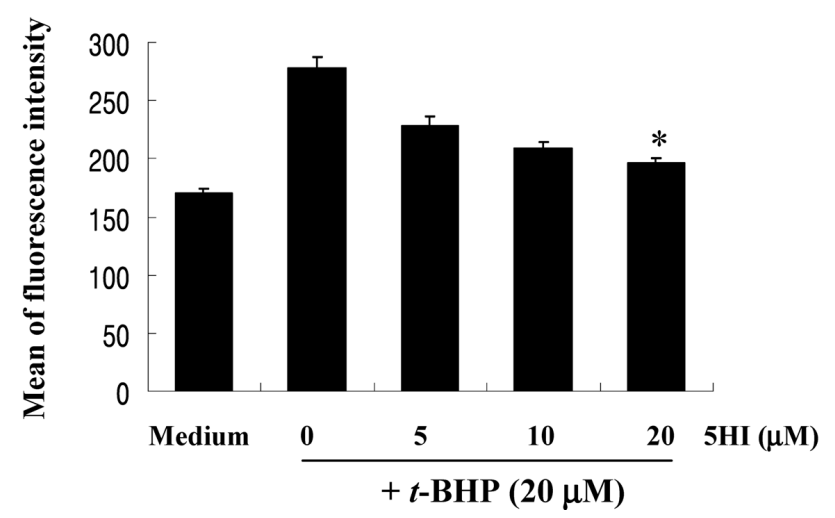

Fig. 4. Effect of $5 \mathrm{HI}$ on the Generation of ROS and $\mathrm{ONOO}^{-}$by $t$-BHP

Cells were pretreated with $5 \mathrm{HI}$ and exposed to $t$-BHP. After $12 \mathrm{~h}$, ROS and $\mathrm{ONOO}^{-}$production was determined using FACS analysis. ROS were detected using DCFH ${ }_{2}$-DA oxidation and fluorescence. The rate of DCF formation was then evaluated by flow cytometry (A). Generation of $\mathrm{ONOO}^{-}$after $12 \mathrm{~h}$ of $t$-BHP exposure (with $2 \mathrm{~h} 5 \mathrm{HI}$ pretreatment) was detected using DHR123 oxidation and fluorescence (B). The results are representative of three independent experiments. $* p<0.05$, $* * p<0.01 v s$. the group treated with $t$ BHP.

largely unknown.

RS are major metabolic products of normal cell signaling, and their dysregulation alter gene expressions that modulate proliferation, cell differentiation, and apoptosis. ${ }^{28)}$ Increased RS generation can cause DNA damage by structural modifications and strand breaks. ${ }^{29)} t$-BHP is widely used to induce oxidative cell damage and is metabolized to ROS. ${ }^{30,31)} t$-BHP is a strong inducer of lipid peroxidation, RS generation, $\mathrm{ONOO}^{-}$generation, and GSH depletion. ${ }^{16)}$ Oxidative damage by $t$-BHP leads to RS generation, lipid peroxidation, as well as DNA condensation and apoptosis. ${ }^{32)}$ We found that $t$ BHP generated RS and $\mathrm{ONOO}^{-}$in fibroblasts, as determined 


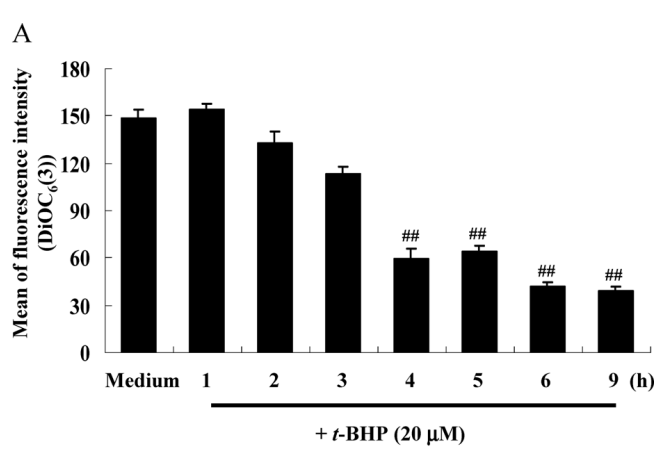

B

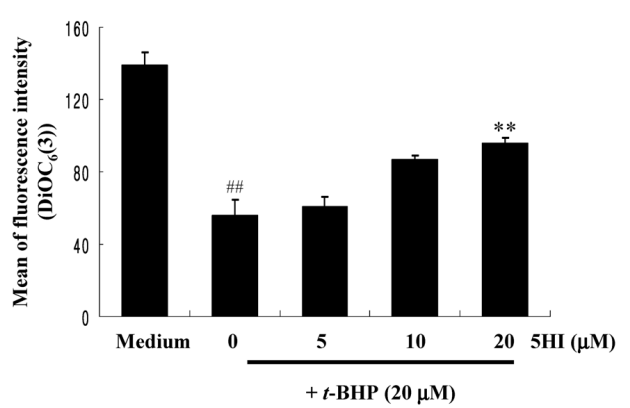

C

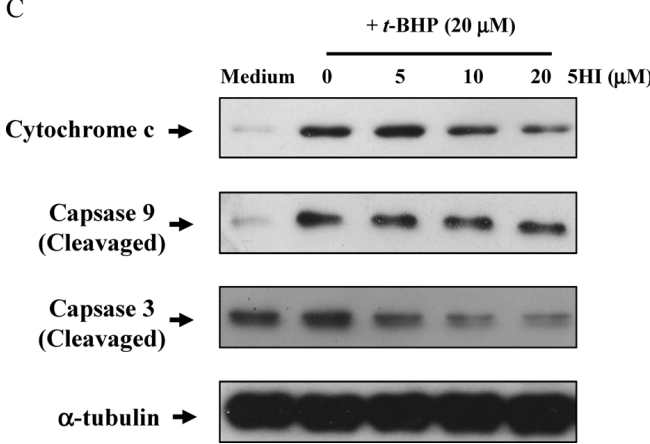

Fig. 5. Effect of 5HI on Caspase Activation, $\Delta \psi \mathrm{m}$, and Cytochrome $c$ Release by $t$-BHP

(A) Cells were incubated with $20 \mu \mathrm{m} t$-BHP for $1,2,3,4,5,6$, or $9 \mathrm{~h}$, and then levels of $\Delta \psi \mathrm{m}$ were measured using flow cytometry. Cells $\left(2 \times 10^{6}\right)$ placed on 6-well plates were pre-incubated with $5 \mathrm{HI}$ for $2 \mathrm{~h}$, followed by $20 \mu \mathrm{M} t$-BHP for $4 \mathrm{~h}$, and then carbocyanines dye $\operatorname{DiOC}_{6}(3)$ for $30 \mathrm{~min}$. Fluorescence was measured using flow cytometry (B). For the detection of cytochrome $c$ and caspase activation, cells were pre-incubated with $5 \mathrm{HI}$ for $2 \mathrm{~h}$, followed by $20 \mu \mathrm{M} t$-BHP treatment for $24 \mathrm{~h}$, and then cell lysates were prepared and blotted with anti-cytochrome $c$, anti-caspase- 9 , anti-caspase-3, and anti- $\alpha$-tubulin antibodies. Bound antibodies were visualized using biotinylated goat anti-mouse $\operatorname{IgG}(\mathrm{C})$. The results shown represent three independent experiments. $\#$ \# $p<0.01 v s$. control, $* * p<0.01 v s$. the group treated by $t$-BHP.

by flow cytometry with fluorescent dyes (Figs. 4A, B). 5HI inhibited $t$-BHP-induced $\mathrm{RS}$ and $\mathrm{ONOO}^{-}$generation. 5HI also dose-dependently inhibited $t$-BHP-induced increases in lipid peroxidation (Fig. 3A) and GSH depletion (Fig. 3B), two markers of oxidative stress-induced cell damage, ${ }^{20,21)}$ which could explain the mechanism by which $5 \mathrm{HI}$ protects cells. GSH depletion by oxidative stress is associated with mitochondrial dysfunction and the induction of apoptosis. ${ }^{33)}$

Apoptosis, programmed cell death, can be initiated via an intrinsic pathway through the mitochondria-mediated death signaling cascade. Mitochondria are a major source of RS, and damaged mitochondria release more RS. In turn, the RS initiate apoptosis by releasing cytochrome $c$ from the mitochondria into the cytosol. Cytochrome $c$ can activate cas- pase-9, which is cleaved and activates caspase-3. After caspase- 3 activation, several specific substrates for caspase- 3 are cleaved, which ultimately leads to cell death. ${ }^{34,35)}$ We first examined cytochrome $c$ release and caspase activation using Western blot analysis. We found that $t$-BHP induced cytochrome $c$ release and cleavage of caspase-9, and casapse- 3 (Fig. 5C), and that $t$-BHP changed the mitochondrial membrane potential $(\Delta \psi \mathrm{m})$. We also found that pretreatment with $5 \mathrm{HI}$ dose-dependently blocked these changes, but not caspase-9 activation (Fig. 5).

In summary, we showed that $5 \mathrm{HI}$ protects against the cytotoxicity induced by $t$-BHP in human fibroblast cell and that $t$ BHP induces toxicity due to lipid peroxidation, GSH depletion and RS generation, leading to mitochondrial dysfunction. We also showed that pretreatment with $5 \mathrm{HI}$ protected against all these alterations. Thus, we propose that $5 \mathrm{HI}$ inhibits $t$-BHP-induced cell death via the regulation of oxidative stress, thereby preserving mitochondria function.

Acknowledgments This work was supported by grant No. R01-2007-000-20852-0 and MRC program No. 20090083538 from the Medical Research Center program of the National Research Foundation of Korea. We are grateful to the 'Aging Tissue Bank' for supplying research resources.

\section{REFERENCES}

1) Yang H. S., Kim S. Y., Choi S. J., Kim K. J., Kim O. N., Lee S. B., Sung K. W., Neurosci. Lett., 338, $72-76$ (2003).

2) Cadenas E., Simic M. G., Sies H., Free Radic. Res. Commun., 6, $11-$ 17 (1989)

3) Oliveira-Silva I. F., Oliveira-Silva I. F., Pinto L., Pereira S. R., Ferraz V. P., Barbosa A. J., Coelho V. A., Gualberto F. F., Souza V. F., Faleiro R. R., Franco G. C., Ribeiro A. M., Behav. Brain Res., 180, 226-234 (2007).

4) Gulati K., Chakraborti A., Ray A., Behav. Brain Res., 183, 226-230 (2007).

5) Chen T., Wong Y. S., Biomed. Pharmacother, 63, 105-113 (2009).

6) Piao M. J., Kang K. A., Zhang R., Ko D. O., Wang Z. H., You H. J., Kim H. S., Kim J. S., Kang S. S., Hyun J. W., Biochim. Biophys. Acta, 1780, 1448-1457 (2008).

7) Simon H. U., Haj-Yehia A., Levi-Schaffer F., Apoptosis, 5, 415-418 (2000).

8) Lee K. J., Choi J. H., Hwang Y. P., Chung Y. C., Jeong H. G., Food Chem. Toxicol., 46, 2445-2450 (2008).

9) Kim D. H., Cho K. H., Moon S. K., Kim Y. S., Kim D. H., Choi J. S., Chung H. Y., J. Pharm. Pharmacol., 57, 1581-1590 (2005).

10) Rosa R. M., Moura D. J., Melecchi M. I., dos Santos R. S., Richter M. F., Camarão E. B., Henriques J. A., de Paula Ramos A. L., Saffi J., Toxicol. In Vitro, 21, 1442-1452 (2007).

11) Zhou Y. J., Zhang S. P., Liu C. W., Cai Y. Q., Toxicol. In Vitro, 23, 288-294 (2009).

12) McGill A., Frank A., Emmett N., Turnbull D. M., Birch-Machin M. A., Reynolds N. J., FASEB J., 19, $1012-1014$ (2005).

13) Draper H. H., Hadley M., Methods Enzymol., 186, 421- 431 (1990).

14) Hissin P. J., Hilf R., Anal. Biochem., 74, 214-226 (1976).

15) Yoo B. K., Choi J. W., Han B. H., Kim W. K., Kim H. C., Ko K. H., Neurosci. Lett., 376, 171-176 (2005).

16) Tripathi M., Singh B. K., Kakkar P., Food Chem. Toxicol., 47, 339347 (2009).

17) Lima C. F., Fernandes-Ferreira M., Pereira-Wilson C., Life Sci., 79, 2056-2068 (2006).

18) Ramos A. A., Lima C. F., Pereira M. L., Fernandes-Ferreira M., Pereira-Wilson C., Toxicol. Lett., 177, 66-73 (2008).

19) Zhu Y. G., Chen X. C., Chen Z. Z., Zeng Y. Q., Shi G. B., Su Y. H., Peng X., Acta Pharmacol. Sin., 25, 1606-1612 (2004).

20) He P., He W., Wang A., Xia T., Xu B., Zhang M., Chen X., Neurotoxicology, 29, 124-129 (2008). 
21) Das S., Khan N., Mukherjee S., Bagchi D., Gurusamy N., Swartz H., Das D. K., Free Radic. Biol. Med., 44, 82-90 (2008).

22) Won J. S., Singh I., Free Radic. Biol. Med., 40, 1875-1888 (2006).

23) Hemnani T., Parihar M. S., Indian J. Physiol. Pharmacol., 42, 440452 (1998).

24) Hakem R., Hakem A., Duncan G. S., Henderson J. T., Woo M., Soengas M. S., Elia A., de la Pompa J. L., Kagi D., Khoo W., Potter J., Yoshida R., Kaufman S. A., Lowe S. W., Penninger J. M., Mak T. W., Cell, 94, 339-352 (1998).

25) Lee C. S., Song E. H., Park S. Y., Han E. S., Neurochem. Int., 43, $147-154$ (2003).

26) Mitsumoto Y., Kobayashi S., Matsushima H., Muroyama A., Yoshimura I., Neurosci. Lett., 463, 22-25 (2009).

27) Zhang S., Ding J. H., Zhou F., Wang Z. Y., Zhou X. Q., Hu G. J., Neurosci. Res., 87, 1230-1239 (2009).

28) Ruiz-Ramos R., Lopez-Carrillo L., Rios-Perez A. D., De Vizcaya-Ruiz A., Cebrian M. E., Mutat. Res., 674, 109-115 (2009).
29) Lee S., Pagoria D., Raigrodski A., Geurtsen W. J., Biomed. Mater. Res. B Appl. Biomater., 83, 391-399 (2007).

30) Lima C. F., Valentao P. C., Andrade P. B., Seabra R. M., FernandesFerreira M., Pereira-Wilson C., Chem. Biol. Interact., 167, 107-115 (2007).

31) Davies M. J., Biochem. J., 257, 603-606 (1989).

32) Miyaguchi C., Muranaka S., Kanno T., Fujita H., Akiyama J., Yoshioka T., Yasuda T., Physiol. Chem. Phys. Med. NMR, 36, 21-35 (2004).

33) Merad-Saidoune M., Boitier E., Nicole A., Marsac C., Martinou J. C., Sola B., Sinet P. M., Ceballos-Picot I., Exp. Neurol., 158, 428-436 (1999).

34) Thayyullathil F., Chathoth S., Hago A., Patel M., Galadari S., Free Radic. Biol. Med., 45, 1403-1412 (2008).

35) Prasad V., Chandele A., Jagtap J. C., Sudheer Kumar P., Shastry P., Free Radic. Biol. Med., 41, 431-442 (2006). 